\title{
RESEARCH ON CONSTRUCTION COST ESTIMATION BASED ON ARTIFICIAL INTELLIGENCE TECHNOLOGY
}

\author{
BIN WANG, JIANJUN YUAN ${ }^{\dagger}$ AND KAYHAN ZRAR GHAFOOR $\ddagger$
}

\begin{abstract}
For the prediction of economic expenses involved in construction industry, cost estimation has become an important aspect of construction management for the prediction of economic expenses and successful completion of the construction work. Cost analysis is crucial and require expertise for accurate and comprehensive estimation. In order to effectively improve the accuracy of construction project cost, this paper establishes an estimation model based on gray BP neural network. It combines the MATLAB toolbox for program design, and learns and tests the input and output of training samples. This article determines the application of grey system theory to optimize the estimation model of Back Propagation (BP) neural network. The viability of the method established in this article, is tested by collecting the engineering cost data in Zhengzhou city and comparing between the standard BP neural network and the gray BP neural network methods. The results show that the average error of the gray system theory optimized BP neural network model designed in this paper is $2.33 \%$. The gray BP neural network model studied in this paper can not only quickly estimate the project cost, but also has high accuracy rate. The outcomes obtained establishes a model with scientific and reasonable construction project cost estimation.
\end{abstract}

Key words: Construction management; BP neural network; artificial intelligence; engineering cost; Zhengzhou city.

AMS subject classifications. $68 \mathrm{~T} 07$

1. Introduction. Construction industry has built as a vital developing sector all around the world. This sector plays an effectual part in economic development of the worldwide economy. Construction industry occupies a large share in the national economy of China as well, especially since the formation of the technological reforms. The share of the construction industry in the national economy has been increasing, and it has a vital role in the process of my country's economic development. The core of the construction industry is construction engineering; therefore, the management of construction engineering has high practical significance [1]. While dealing with the challenges in the construction projects, information technology (IT) equipped with intelligence has emerged as an important aspect for the improvement of technological performance. Intelligent IT techniques are useful in combating the challenges like the selection of qualified contractors for handing the construction projects, prediction of project performance and risk estimation at different construction phases $[2,3]$. The recent technological development has enabled the civil engineers to consider the Artificial Intelligence (AI) scenarios for handling the ambiguous challenges faced by then [4-6].

Cost estimation is the foremost step in a construction project as it is helpful in predicting the economic expenses involved to accomplish the construction work $[7,8]$. The cost assessment is a knowledge intensive task, which is important for ensuring the successful completion of the project [9]. Cost analysis is crucial and require expertise for accurate and comprehensive estimation. The manual estimation is unable to achieve high degree of accuracy and precision in this field, however, inaccurate estimation may lead to construction delay and many other worse scenarios [10-12]. The various factors responsible for switching from the manual construction management towards the AI assisted construction mechanism are depicted in Figure 1.1. The investment perspective of construction project management includes various aspects like preliminary investment estimation, plan design expansion design and construction drawing design stage design budget, project budget in the bidding

\footnotetext{
*Department of construction Management, Chengdu University of Technology, Chengdu, 610059, China (BinWang21@ outlook.com).

${ }^{\dagger}$ Department of construction Management, Chengdu University of Technology, Chengdu, 610059, China (JianjunYuan32@ outlook.com).

${ }^{\ddagger}$ Department of Computer Science, Knowledge University, Erbil 44001, Iraq (kayhan.zrar@knu.edu.iq).
} 


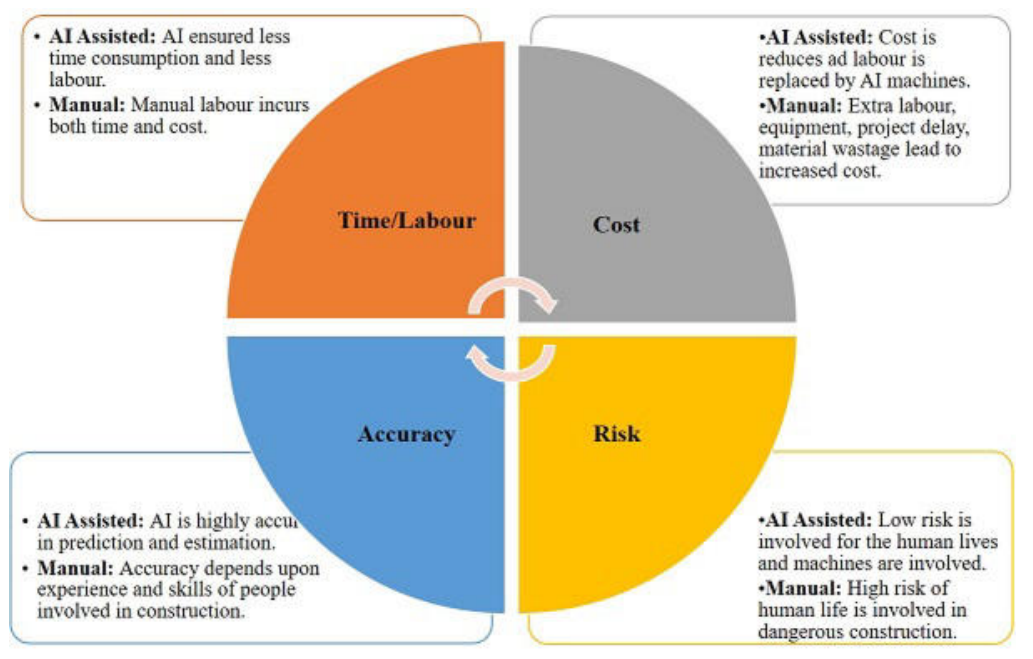

FIG. 1.1. Differentiating features for AI assisted versus manual construction mechanism

stage, project settlement and project final accounts after completion, etc. The focus of construction project management is the investment estimation of construction cost. The investment estimate of the construction cost directly determines the profitability of a project. The cost of construction and installation engineering, that is, the cost of construction engineering, occupies an important position in the investment estimation of construction projects. Therefore, the prediction of construction project cost is of great significance. The project cost system is a very complex task. The traditional manual method of preparing project budgets often results in some miscalculations and omissions. At the same time, the accuracy of the data has also been greatly affected, which will have a great impact on the country. Economic property has a great impact. With the continuous development and change of my country's construction market, the requirements for project budgeting work are also constantly increasing. Therefore, the traditional budget method can no longer meet the actual project budget needs, and computer technology must be used to control the intelligent project cost budget to improve the accuracy of the budget $[13,14]$. Thus, the researchers are encouraged to invest in finding the intelligent solutions for handling the situation of cost estimation.

The research on construction cost estimation based on artificial intelligence technology in this article is of great significance. This article deals with the effective improvement in the construction project cost while improving its accuracy. It established an estimation model based on gray BP neural network, and combines the MATLAB toolbox for program designing. The learning of the neural network takes place and the input and output of the training samples are tested. The novelty of this article lies in determining the application of grey system theory to optimize the estimation model of BP neural network. The feasibility of the proposed method is tested by collecting the engineering cost data in Zhengzhou city and a comparison is done between the standard BP neural network and the gray BP neural network methods. The comparison reveals that the gray BP neural network model utilized in this article not only quickly estimate the project cost, but also provides high accuracy. The remaining article is structures as: literature review is presented in section 2 of the article followed by the research methods briefed in section 3. Section 4 presents the results and discussion of different prediction models and the final conclusion is detailed in section 5 .

2. Literature Review. The study of project cost forecasting models, not only need to have a clear understanding of influencing factors, but also need to have a comprehensive understanding of the current widely used forecasting models. There are many studies on the influencing factors of construction costs. From the comprehensive perspective of the literature published by scholars, they mainly focus on the following aspects.

The construction cost estimation is mainly dependent upon different factors like labor employment, material, equipment, etc. and there are several estimation techniques available in the literature [15-19]. These literature suggests that the cost estimation tenders are required to be prepared precisely over the specific period, 
so as to make the modernized cost estimation self-sufficient. The traditional methods were not upto the mark as they fail to utilize the knowledge of the past projects to tackle the problems in the current scenario. As the actual cost information of the past projects was not known, thus, this leads to slow estimation which are highly inaccurate and tends to variability.

The advancement in the technology led to the initiation of artificial intelligence (AI) based methods for the investigation of multiple as well as non-linear relationships between the construction cost and design parameters, utilizing complex methods and large data volume [20]. Through the applicability of AI platform, fairly accurate cost estimation is possible while using limited amount of information. These machine learning aspects uses the knowledge based and evolutionary hybrid systems for cost estimation [21]. These methods identify the pattern relationships in between the past tender data, thereby reducing the estimation sensitivity and provides the better outcomes. A study performed by Hyari, et al. [22] utilizes the data-driven approach for cost estimation and the influential features are determined using the expert advice on the available data. This study does not provide the actual influence insight of variables on cost estimation and does not reveal the relative importance of variable for cost estimation. Petruseva, et al. [23] utilized the support vector machine (SVM) based approach for the prediction of bidding price in cost estimation. Evaluation on the basis of 54 reports suggests that the SVM based approach provides a better bidding price prediction comparative to the other models. Kim, et al. [24] used various machine learning approaches like SVM, regression and artificial neural network (ANN) for the construction of a school building at the reliable cost. The regression based construction cost estimation was compared to the SVM based method to observe the superiority of machine learning based method in terms of prediction accuracy [25]. Ajayi and Oyedele [26] utilized the concept of structural equation modelling for the cost estimation of construction waste. This paper discusses the scenario of effective cost reduction while reducing the construction waste. Matel, et al. [27] presented the ANN based approach for the estimation of cost in engineering service sector. This method uses the heuristic approach for performance improvement of the model and the approach provides relatively precise cost estimation comparative to the other analogous works. Elmousalami [28] studied the practices and procedures of cost identification using the computation intelligence techniques. The study reviewed various aspect of construction cost on the basis of various paradigms like fuzzy logic, AI, SVM, genetic algorithm, evolutionary programming, etc. AI provides the exceptional performance among all the models used for this approach.

Nguyen, et al. summarized existing research on the application of AI to forecast the performance of several building resources (for example, concrete, wood, steel, and composite materials). It also discusses methods for predicting the fire flame redundancy of certain structural components using AI-based mechanisms. The end of this review provides insights on the advantages of AI technology, its challenges, and recommendations for developing AI technology for evaluating the fire performance and flame redundancy of building materials. An inclusive overview of the current research in the area of fire protection engineering and materials science is presented in this review, which enable the researchers to discover the future perspective of AI [29]. There is an inevitable advent of artificial intelligence in various aspects like engineering industry, construction mechanism, etc. In this context, the technological advent has undergone tremendous expansion, which affects the employment opportunities of Chinese labour forces. The crucial impact of employment on the engineering and construction industry was reviewed by Guang, et al., exploring the perspective of machine learning and intellectual transformation of individuals [30].

This article presents a grey system theory based perspective to determine its application and optimize the estimation model of BP neural network. Through the collection of engineering cost data in Zhengzhou, a training sample set is formed for simulation for establishment of a reliable method for cost estimation. Finally, through example analysis, the prediction accuracy of the grey system. Standard BP neural network method and grey BP neural network method are compared and tested for its prediction accuracy.

\section{Research Methods.}

3.1. BP neural network model construction. Back-Propagation network, abbreviated as BP network, is a very widely used multi-layered feedforward neural network that propagates the errors in the backward direction. The three layers of this network includes the input, hidden and the output layer as depicted in Figure 3.1. 


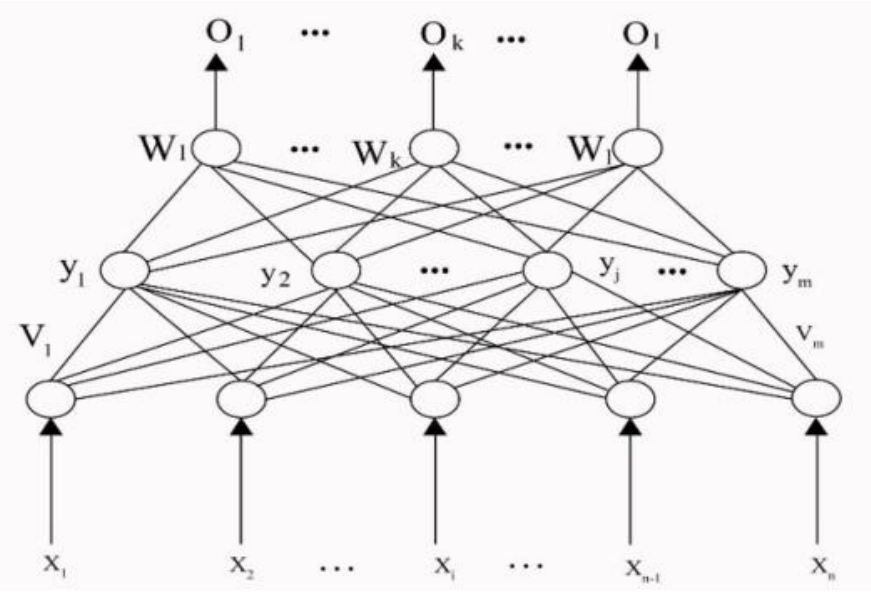

FIG. 3.1. BP neural network model

In the three-layer perceptron, the input vector is

$$
X i=\left(X i_{1}, X i_{2}, \ldots \ldots . X i_{n}\right)^{T}
$$

The variable of the hidden layer is denoted as

$$
Y i=\left(Y i_{1}, Y i_{2}, \ldots \ldots Y i_{m}\right)^{T}
$$

The variable of the output layer is denoted as

$$
O i=\left(O i_{1}, O i_{2}, \ldots \ldots O i_{l}\right)^{T}
$$

The expected vector of the output layer is denoted as

$$
D i=\left(D i_{1}, D i_{2}, \ldots \ldots . D i_{l}\right)^{T}
$$

The weight matrix between the training sample from the input layer to the hidden layer is represented by $\mathrm{Vj}$,

$$
V j=\left(V j_{1}, V j_{2}, \ldots \ldots V j_{m}\right)^{T}
$$

where $V_{j}$ represents the column weight vector that corresponds to the jth neuron in the hidden layer; the weight matrix between the sample from the hidden and the output layer is represented by $W$,

$$
W k=\left(W k_{1}, W k_{2}, \ldots \ldots W k_{l}\right)^{T}
$$

The column vector $W k$ represents the weight vector indicating the $k$ th neuron in the output layer [31].

3.2. Grey Theory. After more than 30 years of development of grey system theory, the structural system of this subject has been basically established. Mainly use grey equations, grey algebra systems, grey matrices, etc. as the theoretical system, grey sequence generation as the method system, grey correlation as the analysis system, and grey model (GM) as the model system to solve "small samples" and "Poor information" and inexperienced uncertain information problems, through data analysis to explore the laws of things [32].

The GM $(1,1)$ model is currently the most significantly used predictor model. Among them, the two "1" respectively represent a first-order equation and a variable. The main idea of grey prediction is: accumulate the original number sequence one or more times to generate a new number sequence, and it is a first-order linear differential equation showing a certain regularity. The steps for the modeling of GM $(1,1)$ are described below.

Let the variable be

$$
x^{0}=\left(x^{0}(1), x^{0}(2),, x^{0}(n)\right)
$$


As a set of original data, accumulate it once to generate a new accumulative sequence (Accumulated Generating Operator abbreviated as AGO), uses:

$$
x^{1}=\left(x^{1}(1), x^{1}(2),, x^{1}(n)\right)
$$

among them

$$
x^{1}(k)=\sigma(i=1)^{k} x^{0}(i)=x^{1}(k-1)+x^{0}(k)
$$

then, Series of mean:

$$
z^{1}(k)=0.5 x^{1}(k)+0.5 x^{1}(k-1) z^{1}=\left(z^{1}(1), z^{1}(2),, z^{1}(n)\right)
$$

That is, the grey differential equation model of $\operatorname{GM}(1,1)$ which is presented in the following equations:

$$
x^{0}(k)+a z^{1}(k)=b
$$

(2) Smoothness inspection

$$
\rho^{k}=\left(x^{0}(k)\right) /\left(x^{0}(k-1)\right)
$$

The judgment condition is: when

$$
k>3 \text { if } \rho^{k}<0.5 \text { then } x^{0} \text { Meet the smoothness test }
$$

(3) Exponential law test

$$
\sigma^{k}(k)=\left(x^{1}(k)\right) /\left(x^{1}(k-1)\right)
$$

The judgment condition is: when

$$
k>3,1<\sigma^{1}(k)<1.5 \text { o'clock, } x^{1}
$$

Satisfying the exponential law for the establishment of $\operatorname{GM}(1,1)$ model.

(4) The equation should be seen as a continuous function of time and it should satisfy

$$
\left(\left(d x^{1}\right) / d t\right)+a x^{1}=b
$$

Then it is the $\operatorname{GM}(1,1)$ prediction model, where $\mathrm{a}$ and $\mathrm{b}$ are undetermined coefficients.

(5) Remember

$$
a^{\prime}=(a, b)^{T}
$$

According to the method of least squares

$$
a^{\prime}=\left(\left(B^{T} B\right)^{-1}\right) B^{T} Y
$$

among them

$$
B=\left[\left[( - z ^ { 1 } ( 2 ) ] [ 1 ] \left[\left(x^{0}(2)\right],\left[( - z ^ { 1 } ( 3 ) ] [ 1 ] \left[\left(x^{0}(3)\right],\left[\left(-z^{1}(n)\right][1]\left[\left(x^{0}(n)\right]\right]\right.\right.\right.\right.\right.\right.
$$

At this time, the time response function of (3-1) is

$$
x^{1}(t)=\left(x^{1}\left(t_{0}\right)-b / a\right) e^{-a\left(t-t_{0}\right)}+b / a
$$

Let $t=k+1$, then the equation becomes

$$
x \perp^{1}(k+1)=\left(x^{0}(1)-b / a\right) e^{-a k}+b / a
$$


The prediction equation and its reduction value is given by,

$$
x \perp^{0}(k+1)=a^{1} x \perp^{1}(k+1)=x \perp^{1}(k+1)-x \perp^{1}(k)=\left(1-e^{a}\right)\left(x^{0}(1)-b / a\right) e^{-a k}
$$

(6) After using the prediction formula to calculate the predicted value, the predicted value must be tested for residual error, that is, the predicted value is compared with the actual value to see whether the overall meets the accuracy requirements. Remember that the residual sequence value is:

$$
\beta(k)=x^{0}(k)-x \perp^{0}(k)
$$

The relative error is:

$$
\varepsilon(k)=(\beta(k)) /\left(x^{0}(k)\right)
$$

The average relative error is:

$$
\varepsilon\left(k_{1}\right)=1 / n\left(\sigma(k=1)^{n}|E(k)|\right.
$$

The model accuracy is shown below:

$$
P=(1-\varepsilon) 100 \%
$$

In general, the accuracy of the model is greater than $80 \%$, and in the case of high requirements, the accuracy of the model is greater than $90 \%$.

\subsection{Cost estimation model based on grey BP neural network.}

3.3.1. Selection of characteristic factors. After analysing the estimated cost and actual cost of many projects, this paper chooses the most common residential projects as the research object, collects multiple residential projects in Zhengzhou, and selects 40 sets of data as the project samples. And through the analysis of the cost composition of the residential project and the parameter changes of the building structure, the 8 main factors affecting the project cost were finally determined: foundation type, structure type, total number of layers of the project, exterior wall decoration, door and window engineering, Interior wall decoration, floor and floor practices, and the location of the project. After quantifying these factors, the grey system processing is used as the input variable of the BP neural network cost control model, and the final unit cost of the entire project is used as the output variable [33].

3.3.2. Quantitative processing of eigenvectors affecting project cost. Use $\mathrm{X} 1 \approx \mathrm{X} 8$ to represent the 8 major factors as the input vector of the network model, and use $\mathrm{O}$ to represent the final project cost as the output vector. The quantification outcomes are depicted in Table 3.1.

3.3.3. Introduction to MATLAB. MATLAB was developed in the 1970 s and was written by Cleve Moler and his colleagues. It was originally designed as an interface program between EISPACK and LINPACK, mainly for the combination of matrices and laboratories, to analyze values, and use programming languages to process large amounts of data efficiently, with high efficiency, good interactivity, and expansion. Strong ability, good portability, easy to learn for users, and faster and more convenient to use. With the development of MATLAB, it is now more suitable for modeling and simulation training.

The MATLAB toolbox provides a fast and efficient platform for research and development of different modules in various fields, utilizing the available toolboxes.Its content covers a wide range, covering signal processing and image processing. Many fields such as processing, economics, mathematics and engineering. Using the MATLAB toolbox can greatly reduce the complexity of programming, and the complete program can be used as a template. Open the toolbox and just enter the actual data and some parameters [34].

Many new results of neural networks are included in the MATLAB toolbox, such as self-organizing networks, perceptron models, feedback networks, adaptive filtering, adaptive training, BP networks, radial basis function networks, etc. $[35,36]$. These toolboxes can quickly Realizing the modeling and solving of the problem provides convenience for users, greatly saves programming time, and users can optimize network design more [37]. 
TABLE 3.1

Engineering feature vector quantization index

\begin{tabular}{|c|c|c|}
\hline Serial number & Influencing factors & Quantitative Indicators \\
\hline$X_{1}$ & Basic Type & $\begin{array}{l}\text { 1-Full house foundation 2-Prefabricated pile foundation 3- } \\
\text { Belt foundation }\end{array}$ \\
\hline$X_{2}$ & Structure Type & $\begin{array}{l}\text { 1-frame structure } 2 \text {-frame-shear structure } 3 \text {-shear wall struc- } \\
\text { ture } 4 \text {-brick-concrete structure }\end{array}$ \\
\hline$X_{3}$ & $\begin{array}{l}\text { Total number of layers of } \\
\text { the project }\end{array}$ & 1- Multi-story 2-Middle-high 3-High 4-Super high-rise \\
\hline$X_{4}$ & Exterior wall decoration & 1-Exterior wall paint 2-Ceramic tile 3-Stone wall \\
\hline$X_{5}$ & Door and window type & $\begin{array}{l}\text { 1-Plastic steel window wooden door 2-Plastic steel window } \\
\text { ordinary anti-theft door }\end{array}$ \\
\hline$X_{6}$ & Interior wall decoration & 1-Rough surface 2-Cement mortar 3-Paint 4-Mixed mortar \\
\hline$X_{7}$ & Floor practice & $\begin{array}{l}\text { 1-Cement mortar floor 2-Fine stone concrete floor } 3 \text {-Floor } \\
\text { tiles }\end{array}$ \\
\hline$X_{8}$ & Project location & $\begin{array}{l}\text { 1-Second ring inner } 2 \text {-Second ring outer third ring inner } 3 \text { - } \\
\text { third ring outer fourth ring inner } 4 \text {-fourth ring outer }\end{array}$ \\
\hline
\end{tabular}

TABLE 4.1

The original number of sample samples

\begin{tabular}{|l|l|l|l|l|l|l|l|l|l|}
\hline Category & $X_{1}$ & $X_{2}$ & $X_{3}$ & $X_{4}$ & $X_{5}$ & $X_{6}$ & $X_{7}$ & $X_{8}$ & Output(yuan/m $\left.{ }^{2}\right)$ \\
\hline \hline 1 & 1 & 3 & 3 & 3 & 3 & 2 & 1 & 3 & 1443.65 \\
\hline 2 & 1 & 3 & 3 & 3 & 3 & 4 & 2 & 3 & 1562.21 \\
\hline 3 & 1 & 2 & 2 & 3 & 2 & 1 & 2 & 3 & 1243.57 \\
\hline 4 & 1 & 3 & 3 & 3 & 4 & 3 & 1 & 3 & 1687.43 \\
\hline 5 & 1 & 3 & 4 & 3 & 4 & 3 & 2 & 3 & 1898.16 \\
\hline
\end{tabular}

3.3.4. Grey system's processing of data. Based on the establishment of a sample database of residential projects in Zhengzhou, this paper has determined the main influencing factors of 8 projects, and selected 40 sets of sample data, of which 30 sets are used as training samples and 10 sets are used as test samples. The sample is subjected to a grey accumulation, and MATLAB is utilized to model and simulate the data. Finally, the test data is justified, and the error meets the requirements, which proves that it is feasible to optimize the BP neural network with grey system theory in reality.

\section{Results and Discussion.}

4.1. Project Overview. Initially a comparative investigation of various projects is done in terms of different factors and after this comparison, the most common residential projects Zhengzhou city, China is selected for this work. The quantitative data is depicted in Table 4.1.

It is expressed in Table 4.1, that the project includes a set of data which is subdivided into different categories. After quantification of various factors affecting the project cost like foundation type, structure type, project location, etc. the grey system processing is used as the input variable of the three different cost control prediction models, and the final unit cost of the entire project is obtained.

4.2. Comparison of the three models. A comparative analysis of three different prediction models is done. The models utilized for the study are grey prediction model, standard BP neural network model and the grey BP neural network model.

4.2.1. GM(1,1) grey prediction model. The predicted value of the grey prediction model cost is observed for various samples which is shown in Table 4.2 . 
TABLE 4.2

Analysis of actual versus predicted values of samples

\begin{tabular}{|l|l|l|l|}
\hline Serial number & Actual value & Predictive value & Relative error (\%) \\
\hline \hline 1 & 1443.65 & 1244.67 & 13.78 \\
\hline 2 & 1562.21 & 1371.31 & 12.22 \\
\hline 3 & 1243.57 & 1510.85 & 21.49 \\
\hline 4 & 1687.43 & 1664.58 & -1.35 \\
\hline 5 & 1898.16 & 1833.95 & -3.38 \\
\hline
\end{tabular}

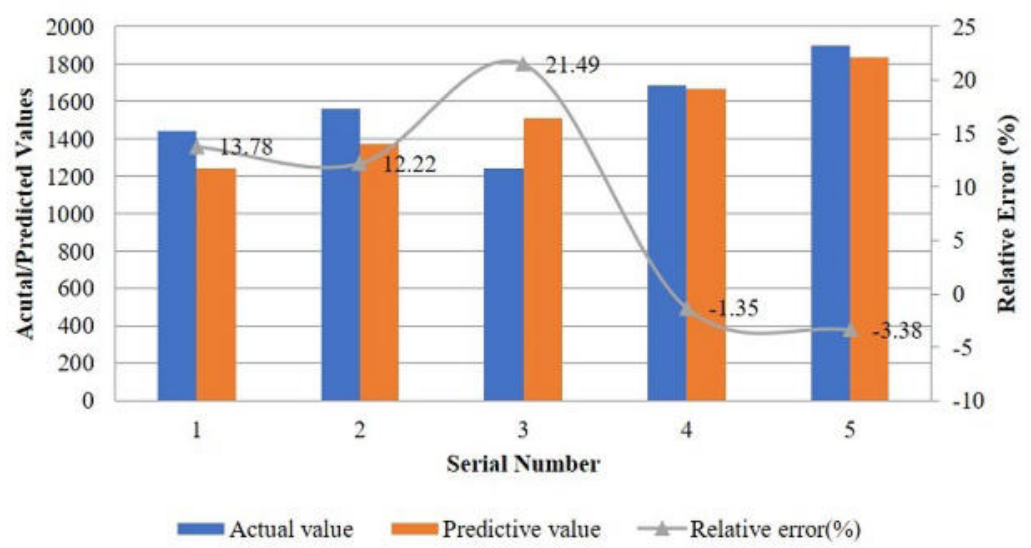

FIG. 4.1. Graphical comparative analysis of actual values, predicted values and relative error for grey prediction model

TABLE 4.3

Normalized data of example samples

\begin{tabular}{|l|l|l|l|l|l|l|l|l|l|}
\hline No. & $X_{1}$ & $X_{2}$ & $X_{3}$ & $X_{4}$ & $X_{5}$ & $X_{6}$ & $X_{7}$ & $X_{8}$ & Output \\
\hline \hline 1 & 0.0000 & 1.0000 & 0.5000 & 0.0000 & 0.5000 & 0.3333 & 0.0000 & 0.0000 & 0.3057 \\
\hline 2 & 0.0000 & 1.0000 & 0.5000 & 0.0000 & 0.5000 & 1.0000 & 1.0000 & 0.0000 & 0.4868 \\
\hline 3 & 0.0000 & 0.0000 & 0.0000 & 0.0000 & 0.0000 & 0.0000 & 1.0000 & 0.0000 & 0.0000 \\
\hline 4 & 0.0000 & 1.0000 & 0.5000 & 0.0000 & 1.0000 & 0.6667 & 0.0000 & 0.0000 & 0.6781 \\
\hline 5 & 0.0000 & 1.0000 & 1.0000 & 0.0000 & 1.0000 & 0.6667 & 1.0000 & 0.0000 & 1.0000 \\
\hline
\end{tabular}

It is evident from the table that the average relative error of the model is $10.44 \%$, and the accuracy of the model obtained is $89.56 \%$. Although it meets the general requirements of accuracy, the predicted value is not accurate enough, and the error fluctuates greatly, which cannot meet the accuracy requirements of cost estimation. It is graphically represented in respect of actual value, prediction value and relative error in Figure 4.1.

4.2.2. Training of standard BP neural network. The standard BP neural network is also trained for the selected samples and the data of example samples is normalized initially. The normalized data of the example sample is depicted in Table 4.3 .

This normalized sample data is utilized for the training of BP neural network. MATLAB software is used to process the data and the output value obtained is compared with the actual value as shown in Table 4.4.

The outcomes observed for the standard BP neural network model are depicted in Table 4.4 and are graphically presented in terms of actual value, predicted value and the relative error (percentage) in Figure 4.2. From the graphical comparison, it is revealed that the relative error obtained by using the BP neural network-based method provides much reduced value of relative error comparative to the grey prediction model. The relative error has decreased from $10.44 \%$ to $3.64 \%$ which validates the accurate prediction of standard BP 
TABLE 4.4

Analysis of actual versus predicted values of samples

\begin{tabular}{|l|l|l|l|}
\hline Serial number & Actual value & Predictive value & Relative error (\%) \\
\hline \hline 1 & 1443.65 & 1510.45 & 4.63 \\
\hline 2 & 1562.21 & 1623.29 & 3.91 \\
\hline 3 & 1243.57 & 1202.91 & -3.27 \\
\hline 4 & 1687.43 & 1627.02 & -3.58 \\
\hline 5 & 1898.16 & 1951.69 & 2.82 \\
\hline
\end{tabular}

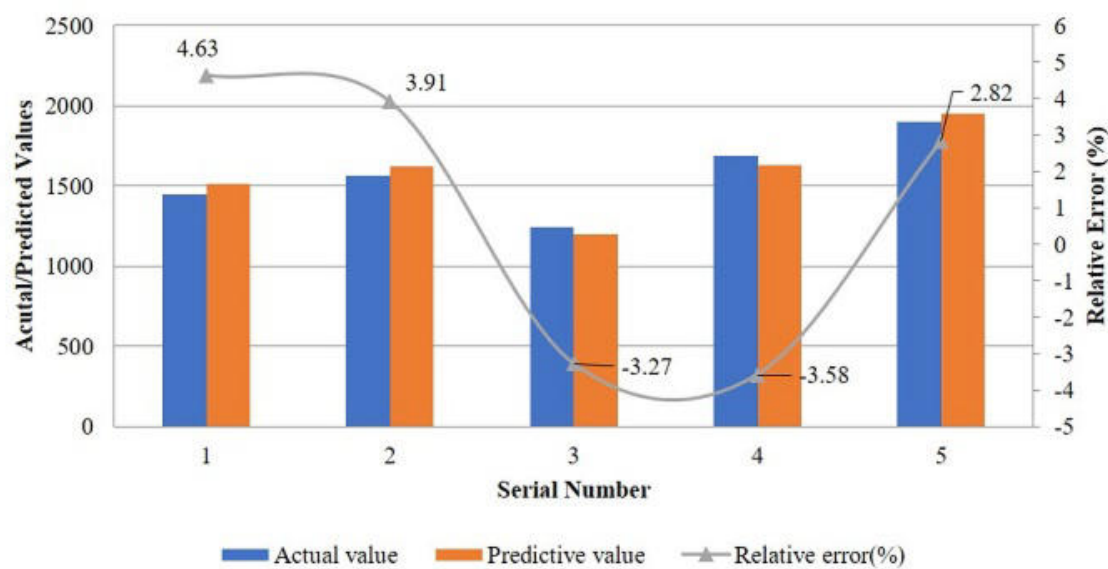

FIG. 4.2. Graphical comparative analysis of actual values, predicted values and relative error for standard BP neural network model

neural network-based method.

4.2.3. Training of grey BP neural network. For training the grey BP neural network model, grey one-time accumulation processing is performed on the example samples which is shown in Table 4.5.

The outcomes obtained after grey one-time accumulation processing are then normalized in order to obtain the normalized input and output vectors for further processing. The samples were normalized, as depicted in Table 4.6.

MATLAB software is used to process the normalized data, and then the obtained data is de-normalized followed by the grey one-time accumulative subtraction to obtain the predicted value. The obtained data is shown in Table 4.7 and the graphical presentation is depicted in Figure 4.3.

The comparison reveals that the mean relative error is further reduced from $3.64 \%$ in case of standard BP neural network based method to $2.33 \%$ for grey BP neural network model establishing its feasibility for cost prediction and estimation.

It is evident from Table 4.3 to Table 4.8 that the standard BP neural network method and the BP neural network method optimized by grey system theory have certain errors. The error of the grey BP neural network model is smaller than the error of the GM $(1,1)$ prediction model and the standard BP neural network model, and the prediction accuracy is relatively high. It has a particular ideal set reference value for the early prediction of the project cost. This comparison is clearly depicted in Table 4.8.

The prediction results are compared and error mean values of the GM $(1,1)$ model, BP neural network model, and grey BP neural network model respectively, is depcited in Table 4.8.

This article selects representative buildings, quantifies the characteristics of buildings, then processes quantitative data using GM $(1,1)$ prediction model, standard BP neural network method and BP neural network method optimized by grey system theory, and trains and tests the actual samples in combination with MATLAB toolbox, obtains prediction values, and calculates the error mean of $10.44 \%, 3.64 \%$ and $2.33 \%$, respectively. 
TABLE 4.5

The sample values of the examples accumulated once in grey

\begin{tabular}{|l|l|l|l|l|l|l|l|l|l|}
\hline Category & $X_{1}$ & $X_{2}$ & $X_{3}$ & $X_{4}$ & $X_{5}$ & $X_{6}$ & $X_{7}$ & $X_{8}$ & Output \\
\hline \hline 1 & 1 & 3 & 3 & 3 & 3 & 2 & 1 & 3 & 1443.65 \\
\hline 2 & 2 & 6 & 6 & 6 & 6 & 6 & 3 & 6 & 3005.86 \\
\hline 3 & 3 & 8 & 8 & 9 & 8 & 7 & 5 & 9 & 4249.43 \\
\hline 4 & 4 & 11 & 11 & 12 & 12 & 10 & 6 & 12 & 5936.86 \\
\hline 5 & 5 & 14 & 15 & 15 & 16 & 13 & 8 & 15 & 7835.02 \\
\hline Sequence minimum & 1 & 3 & 3 & 3 & 3 & 2 & 1 & 3 & 1443.65 \\
\hline Sequence maximum & 5 & 14 & 15 & 15 & 16 & 13 & 8 & 15 & 7835.02 \\
\hline
\end{tabular}

TABLE 4.6

Normalized data of example samples for grey BP Neural Network

\begin{tabular}{|l|l|l|l|l|l|l|l|l|l|}
\hline No. & $X_{1}$ & $X_{2}$ & $X_{3}$ & $X_{4}$ & $X_{5}$ & $X_{6}$ & $X_{7}$ & $X_{8}$ & Output \\
\hline \hline 1 & 0.0000 & 0.0000 & 0.0000 & 0.0000 & 0.0000 & 0.0000 & 0.0000 & 0.0000 & 0.0000 \\
\hline 2 & 0.2500 & 0.2727 & 0.2500 & 0.2500 & 0.2308 & 0.3636 & 0.2857 & 0.2500 & 0.2444 \\
\hline 3 & 0.5000 & 0.4545 & 0.4167 & 0.5000 & 0.3846 & 0.4545 & 0.5714 & 0.5000 & 0.4390 \\
\hline 4 & 0.7500 & 0.7272 & 0.6667 & 0.7500 & 0.6923 & 0.7272 & 0.7143 & 0.7500 & 0.7030 \\
\hline 5 & 1.0000 & 1.0000 & 1.0000 & 1.0000 & 1.0000 & 1.0000 & 1.0000 & 1.0000 & 1.0000 \\
\hline
\end{tabular}

TABLE 4.7

Comparison of actual values and predicted values of samples

\begin{tabular}{|l|l|l|l|}
\hline Serial number & Actual value & Predictive value & Relative error (\%) \\
\hline \hline 1 & 1443.65 & 1405.29 & -2.65 \\
\hline 2 & 1562.21 & 1531.28 & -1.98 \\
\hline 3 & 1243.57 & 1272.67 & 2.34 \\
\hline 4 & 1687.43 & 1723.03 & 2.11 \\
\hline 5 & 1898.16 & 1947.13 & 2.58 \\
\hline
\end{tabular}

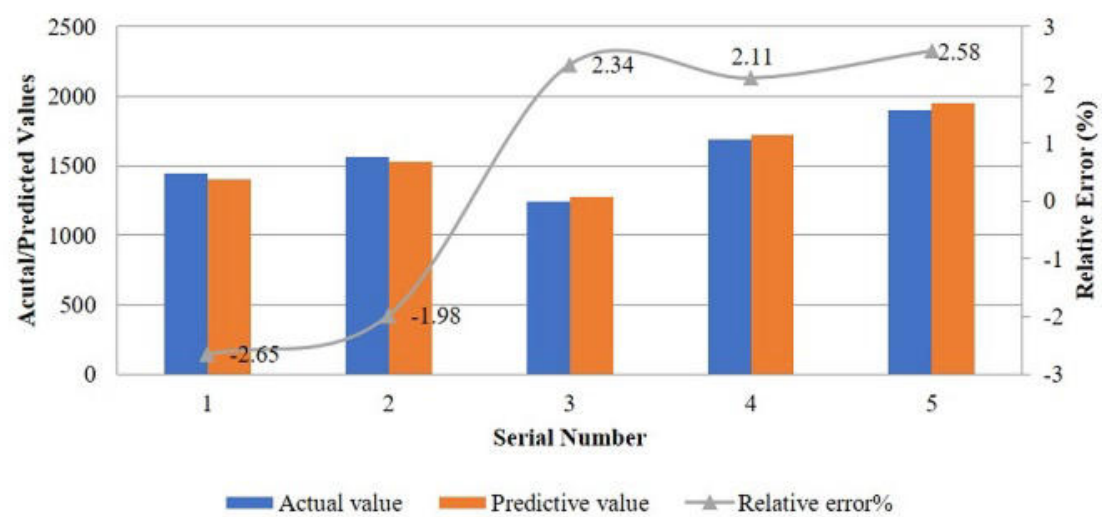

FIG. 4.3. Graphical comparative analysis of actual values, predicted values and relative error for grey BP neural network model

Finally, the three algorithms are compared to show that the improved BP neural network method is better than the GM $(1,1)$ prediction model and the standard BP neural network method.

5. Conclusion. This article analyzes the advantages and disadvantages of BP neural network, puts for- 
TABLE 4.8

Comparison of three algorithms

\begin{tabular}{|l|l|l|l|l|}
\hline Serial number & Actual value & GM(1,1) & BP Neural Network & grey BP Neural Network \\
\hline \hline 1 & 1443.65 & 1443.65 & 1510.45 & 1405.29 \\
\hline 2 & 1562.21 & 1371.31 & 1623.29 & 1531.282 \\
\hline 3 & 1243.57 & 1510.85 & 1202.91 & 1272.67 \\
\hline 4 & 1687.43 & 1664.58 & 1627.02 & 1723.03 \\
\hline 5 & 1898.16 & 1833.95 & 1951.69 & 1947.13 \\
\hline
\end{tabular}

ward the use of gray system theory and analyzes its advantages and disadvantages, comprehensively utilizing the advantages of both. This article determines the application of grey system theory to optimize the estimation model of BP neural network. The feasibility of this method in cost estimation is verified by collecting engineering cost data from Zhengzhou City to form a training sample set for simulation training, and through case analysis, the comparison is done for the prediction accuracy of gray system theory, the standard BP neural network method and gray BP neural network method. This paper, combined with the GM $(1,1)$ model, standard BP neural network model and gray BP neural network model in gray system theory, establishes an estimation model for the Sunshine City project in Zhengzhou. The analysis verifies that the gray BP neural network model can not only estimate the engineering cost quickly, but also has high precision, making it a scientific and reasonable construction cost estimation model. The future perspectives of this article which are still needed to be explored are; analysis of various influencing factors of project cost like requirement of a large amount of project examples for verification, the selection of factors affecting the project cost needs to be further studied in the future part of this work. The future scope of application of this method is to require the location of the project to be estimated to have similar project examples, so that the total project cost estimated by these data should be consistent with the previous forecast results.

\section{REFERENCES}

[1] Tijani, K., Car-Pui, D., Perac, M., Cost estimation in road construction using artificial neural network, Neural Computing and Applications, 32(13), 9343-9355, 2020.

[2] Thomas, S. R., Lee, S. H., Spencer, J. D., Tucker, R. L., Chapman, R. E., Impacts of design/information technology on project outcomes, Journal of Construction Engineering and Management, 130(4), 586-597, 2004.

[3] Albogamy, A., Scott, D., Dawood, N., Bekr, G., Addressing crucial risk factors in the Middle East construction industries: a comparative study of Saudi Arabia and Jordan, In Sustainable Building Conference Coventry University, West Midlands, UK, 2013.

[4] Melhem, H. G., Issa, R. R., Technical council for computing and information technology, 2008.

[5] Ren, X., Li, C., Ma, X., Chen, F., Wang, H., Sharma, A., Masud, M., Design of Multi-Information Fusion Based Intelligent Electrical Fire Detection System for Green Buildings, Sustainability, 13(6), 3405, 2021.

[6] Parmee, I. C., Computational Intelligence and Civil Engineering-Perceived Problems and Possible Solutions, In Towards a Vision for Information Technology in Civil Engineering (pp. 1-12), 2004.

[7] Poongodi, M., Sharma, A., Vijayakumar, V., Bhardwaj, V., Sharma, A. P., Iqbal, R., Kumar, R., Prediction of the price of Ethereum blockchain cryptocurrency in an industrial finance system, Computers amd Electrical Engineering, $81,106527,2020$

[8] Holm, L., Construction cost estimating: process and practices, Prentice Hall, 2005.

[9] Sharma, A., Kumar, R., Computation of the reliable and quickest data path for healthcare services by using service-level agreements and energy constraints, Arabian Journal for Science and Engineering, 44(11), 9087-9104, 2019.

[10] Staub-French, S., Fischer, M., Kunz, J., Paulson, B., A generic feature-driven activity-based cost estimation process, Advanced Engineering Informatics, 17(1), 23-39, 2003.

[11] Shane, J. S., Molenafr, K. R., Anderson, S., Schexnayder, C., Construction project cost escalation factors, Journal of Management in Engineering, 25(4), 221-229, 2009.

[12] Dhiman, G., Singh, K. K., Soni, M., Nagar, A., Dehghani, M., Slowik, A., Cengiz, K., MOSOA: a new multi-objective seagull optimization algorithm, Expert Systems with Applications, 167, 114150, 2021.

[13] Priti, M., SAlunkhe, A. A., Comparative analysis of construction cost estimation using artificial neural networks,Xi'an Dianzi Keji Daxue Xuebao/Journal of Xidian University, 14(7), 1287-1305, 2020.

[14] Abdel-Basset, M., Ali, M., Atef, A., Resource levelling problem in construction projects under neutrosophic environment, Journal of supercomputing, 76(2), 964-988, 2020.

[15] ElkJAer, M., Stochastic budget simulation, International Journal of Project Management, 18(2), 139-147, 2000. 
[16] Burke, R., Project management: planning and control techniques, New Jersey, USA, 26, 2013.

[17] Zwaving, J. O., SProbablistic estimating of engineering costs.

[18] NASA Executive Cost Analysis Steering Group, INASA cost estimating handbook. NASA, 63(4), 2015.

[19] Steen, E., Assessing the influence of tender and project characteristics on project performance, (Master's thesis, University of Twente), 2018.

[20] Günaydin, H. M., DoĞAn, S. Z. , A neural network approach for early cost estimation of structural systems of buildings, International journal of project management, 22(7), 595-602, 2004.

[21] Elfaki, A. O., Alatawi, S., Abushandi, E., Using intelligent techniques in construction project cost estimation: 10-year survey, Advances in Civil Engineering, 2014.

[22] Hyari, K. H., Al-Daraiseh, A., El-Mashaleh, M. , Conceptual cost estimation model for engineering services in public construction projects, Journal of Management in Engineering, 32(1), 04015021, 2016.

[23] Petruseva, S., Sherrod, P., Pancovska, V. Z., Petrovski, A., Predicting bidding price in construction using support vector machine, TEM Journal, 5(2), 143, 2016.

[24] Shenab, T., Mahani, M., Hybrid Case-Based Reasoning Approach to Value Engineering in Road Rehabilitation and Traffic Improvement Projects, International Journal of Applied Engineering Research, 11(23), 11199-11206, 2016.

[25] Petruseva, S., Zileska-Pancovska, V., Žujo, V., Brkan-Vejzović, A., Construction costs forecasting: comparison of the accuracy of linear regression and support vector machine models, Technical Gazette, 24(5), 1431-1438, 2017.

[26] Ajayi, S. O., Oyedele, L. O., Waste-efficient materials procurement for construction projects: A structural equation modelling of critical success factors, Waste Management, 75, 60-69, 2018.

[27] Matel, E., Vahdatikhaki, F., Hosseinyalamdary, S., Evers, T., Voordijk, H., An artificial neural network approach for cost estimation of engineering services, International journal of construction management, 1-14, 2019.

[28] Elmousalami, H. H., Artificial intelligence and parametric construction cost estimate modeling: state-of-the-art review, Journal of Construction Engineering and Management, 146(1), 03119008, 2020.

[29] Nguyen, H. T., Nguyen, K. T. Q., Le, T. C., Zhang, G., Review on the use of artificial intelligence to predict fire performance of construction materials and their flame retardancy, Molecules, 26(4), 1022, 2021.

[30] Gunng, C., Development of migrant workers in construction based on machine learning and artificial intelligence technology, Journal of Intelligent and Fuzzy Systems(25), 1-12, 2020.

[31] Poyet, P., ANNE ARIE DUBOIS, Delcambre, B., Artificial intelligence software engineering in building engineering, Computer-Aided Civil and Infrastructure Engineering, 5(3), 167-205, 1990.

[32] Pena, M. L. C., Adrián Carballal, Rodriguez-Fernandez, N., Santos, I., Romero, J., Artificial intelligence applied to conceptual design. a review of its use in architecture, Automation in Construction, 124(3-4), 30, 2021.

[33] Gretz, S., Friedman, R., Cohen-Karlik, E., Toledo, A., Slonim, N., A large-scale dataset for argument quality ranking: construction and analysis, Proceedings of the AAAI Conference on Artificial Intelligence, 34(5), 7805-7813, 2020.

[34] YI, X., WU, J., Research on safety management of construction engineering personnel under "big data + artificial intelligence", Open Journal of Business and Management, 08(3), 1059-1075, 2020.

[35] Kaushik, M., Gupta, S. H., Balyan, V., Optimization of Cooperative In Vivo Sensor Network Operating at Terahertz Frequency, IEEE Sensors Journal, 2021.

[36] Kaushik, M., Gupta, S. H., Balyan, V., Evaluating threshold distance by using eigen values and analyzing its impact on the performance of WBAN, In 2019 6th International Conference on Signal Processing and Integrated Networks (SPIN) (pp. 864-867), 2019.

[37] Wu, S. M., Jose, M., Hallermeier, K., Rennert, O. M., Chan, W. Y., The application of artificial intelligence, robotics and image processing to civil engineering, building engineering, architecture, urban design and urban planning : delft, the netherlands, Automation in Construction, 1(4), 333-4, 1998.

Edited by: Pradeep Kumar Singh

Received: Apr 24, 2021

Accepted: Sep 4, 2021 